\title{
DIGITALISATION IN TIMES OF COVID-19 - THE BEHAVIOURAL SHIFTS IN ENTERPRISES AND INDIVIDUALS IN THE SECTOR OF BIOECONOMY
}

\author{
Sandija Zeverte-Rivza ${ }^{1}$, Dr.oec.; Ina Gudele ${ }^{2}$, Mg.oec.
}

${ }^{1}$ Celteh Ltd; Latvia University of Life Sciences and Technologies, ${ }^{2}$ Celteh Ltd

\begin{abstract}
Although our daily life within a modern society is unimaginable without the use of information and communication technologies (ICT), the COVID-19 crisis really highlighted the ways we can maximise the use of digital technologies in optimising our work in distance working conditions with limited ability to contact each other physically, make direct sales and ensure the physical document rotation. All these limitations have pushed the governmental organisations, enterprises, and households to utilize numerous means of digital services and digital transformation aspects that had been started to be used, but the last year has rapidly pushed forward such aspects of digitalisation as digital sales, distance work using co-working platforms and cloud storage, electronic signature of documents and others. This study aims to assess the trends in online sales and use of e-tools from the perspective of enterprises and individuals in Europe in the sector of bioeconomy with the focus of the Baltic States and Latvia that could be used to strengthen the digitalisation component during and post COVID-19. In this paper, the authors have reviewed the scientific literature, policy planning documents, analysed relevant statistical data, performed statistical analysis, and estimated the tendency of the use of eSignatures in Latvia by applying the Holt's two-parameter model of exponential smoothing. The main results indicate a significant increase in motivation towards digitalisation that has increased rapidly in line with the necessity for an online shopping and distance work setting. Authors suggest supporting this tendency also in the afterCOVID life, which would have a great impact on the overall digital transformation and potential to unlock new markets for bio-based products.
\end{abstract}

Key words: digitalisation, bioeconomy, entrepreneurship, COVID-19, e-commerce.

JEL code: 013

\section{Introduction}

Digital transformation is an ongoing process that has intensified in the past decade, but the year 2020 with all social and physical limitations has been a real turning point and it has pushed governmental organisations, enterprises, and households to utilize numerous means of digital services and digital transformation aspects. Digitalisation has had a substantial impact on e-commerce, distance work using co-working platforms and cloud storage, electronic signatures of documents, and others.

ICT are essential to perform international processes, therefore the increase in the importance level and frequency of use of these technologies allows perceiving better results in international business and exportability. Thus, for some businesses this time can provide an opportunity for internationalisation and expanding of their market, although the change of behaviour towards a wider range of everyday produce bought online can open a huge market for producers of bio-based products also nationally. Digitalisation goes hand in hand with the changes in the business model, it allows to gain new markets nationally and internationally. Scholars from different research areas have recognized the potential of new business models in promoting competitive advantages of enterprises (Clauss, 2017). Digitalization is a new source for business model innovation and leads to a higher degree of enterprise competitiveness (Schallmo et al., 2017, Pelše, Zeverte-Rivza, 2015). In previous studies it has been determined that in Latvia the most important factor groups that affect the use of e-commerce are technological development, organisational, legislation, and economic factors. At the same time, language and content barriers as well as the lack of secure payment infrastructure are considered significant barriers avoiding to adapt e-commerce (Jekabsone I., Gudele I., 2020)

1 Sandija Zēverte-Rivza, e-mail: Sandija.Rivza@llu.Iv 
This study aims to determine the tendencies of digitalisation in the sector of bioeconomy that could be used to strengthen the digitalisation component during and post COVID-19. The authors have set the hypothesis - the current situation has increased the motivation towards digital transformation in enterprises and will the determine the digitalisation trends for the future. Research tasks are to: (1) review the scientific literature, regulatory and policy planning documents regarding the digitalisation of enterprises in the bioeconomy sector; (2) analyse the relevant statistical data; (3) apply a Holt's two-parameter model of exponential smoothing to estimate the tendency of the use of eSignatures.

For this study, the authors have applied monographic and statistical research methods and used the scientific literature sources; policy planning documents; statistics databases (Eurostat) and data from Latvia State Radio and Television Centre about the use of e-signatures.

\section{Research results and discussion}

According to the Digital Economy and Society Index (DESI) 2020 report, which is based on the 2019 data and assesses the status of the digital economy and society prior to the coronavirus pandemic, only $10 \%$ of internet users in Latvia sold goods online, which is much lower as the European Union (EU) average of $23 \%$. The leading countries on ' 4 a business digitisation' are Finland, the Netherlands, and Belgium, with scores above 60 points. Bulgaria, Hungary, Poland, Romania, Latvia, and Slovakia lag behind in the adoption of e-business technologies, scoring below 40 points. Latvia also has the 5th lowest score in ecommerce (DESI 2020, 2020).

The data from Eurostat (Fig .1) indicate that in 2020 there has been a slight increase in enterprises with e-commerce sales - from $20 \%$ in 2019 to $21 \%$ in 2020 in the EU 27 countries with a higher growth of countries like Croatia, Spain, Romania and Slovakia. However, there is also a decline in Finland, Belgium, France, The Netherlands, Estonia and Luxembourg.

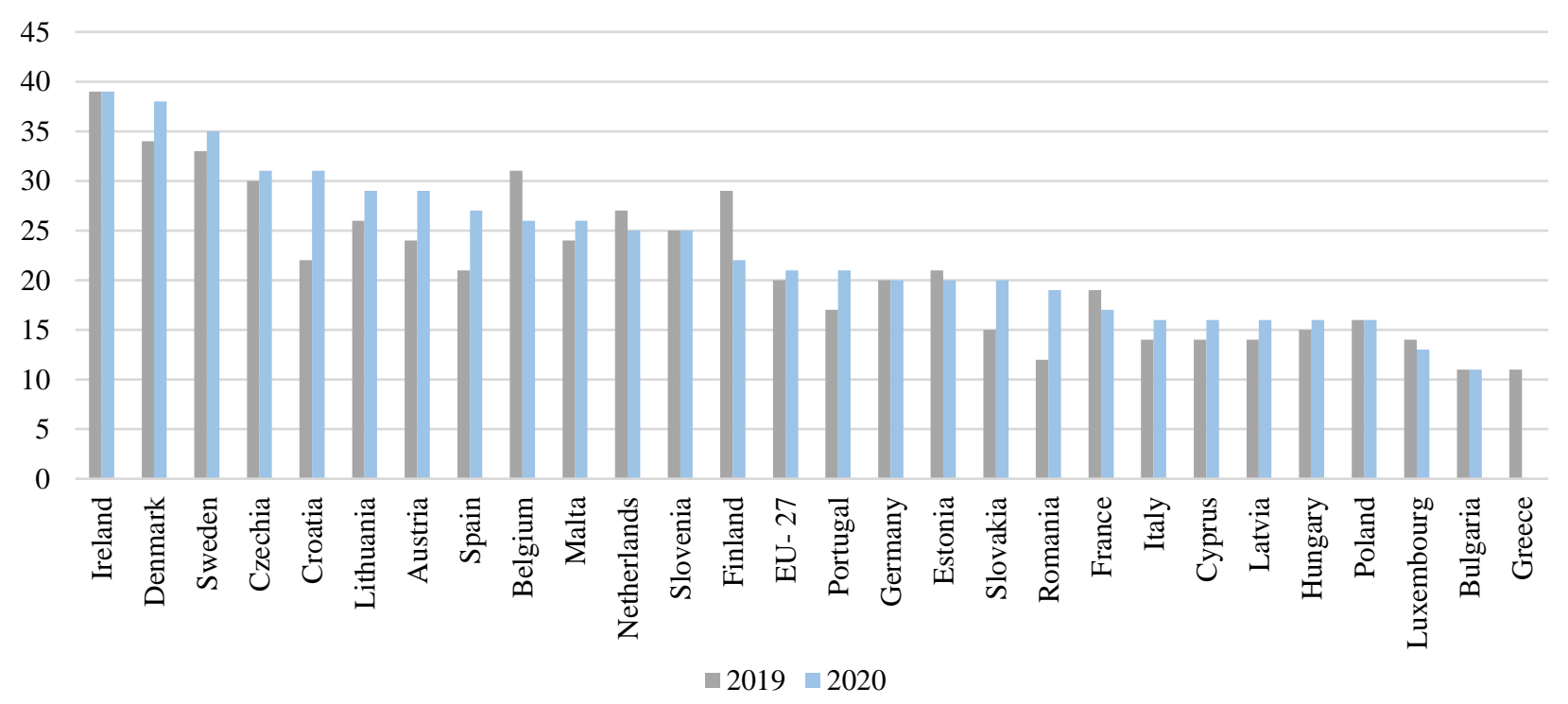

Source: author's creation based on the data from Eurostat, 2021

Fig. 1. Enterprises with e-commerce sales percentage of enterprises in EU-27 countries, 2019-2020

Although the percentage of enterprises with e-commerce sales has increased slightly (Fig. 2.), the percentage of individuals that are making internet purchases has increased considerably comparing 2019 to 2020. The highest increase in internet purchases by individuals is experienced in Czechia - by $16 \%$, Hungary - $14 \%$, and Croatia by $11 \%$. All of these countries were below the EU-27 average in 2019, and 
this increase has brought Czechia well above the EU-27 average in 2020 and approached the other two member states to the EU-27 average as well. The increase of internet purchases by individuals in the Baltic States are rather moderate - by $4 \%$ in Lithuania and Latvia and only $1 \%$ in Estonia. Although the purchasing activity of individuals in Estonia was already high in 2019 - $56 \%$ and increased to $57 \%$ in 2020, which is well above the EU-27 average. In 2020, the most active internet customers are from Denmark (79 \%), the Netherlands (77\%), Germany (75\%), and Sweden (73\%) and the countries comparatively lagging behind are Romania and Bulgaria with $22 \%$ and $16 \%$ respectively. This indicates not only the willingness and readiness of individuals to shop online, but more importantly, the wideness or narrowness of the offered goods online as well as the availability and terms for online orders such as shipping fees.

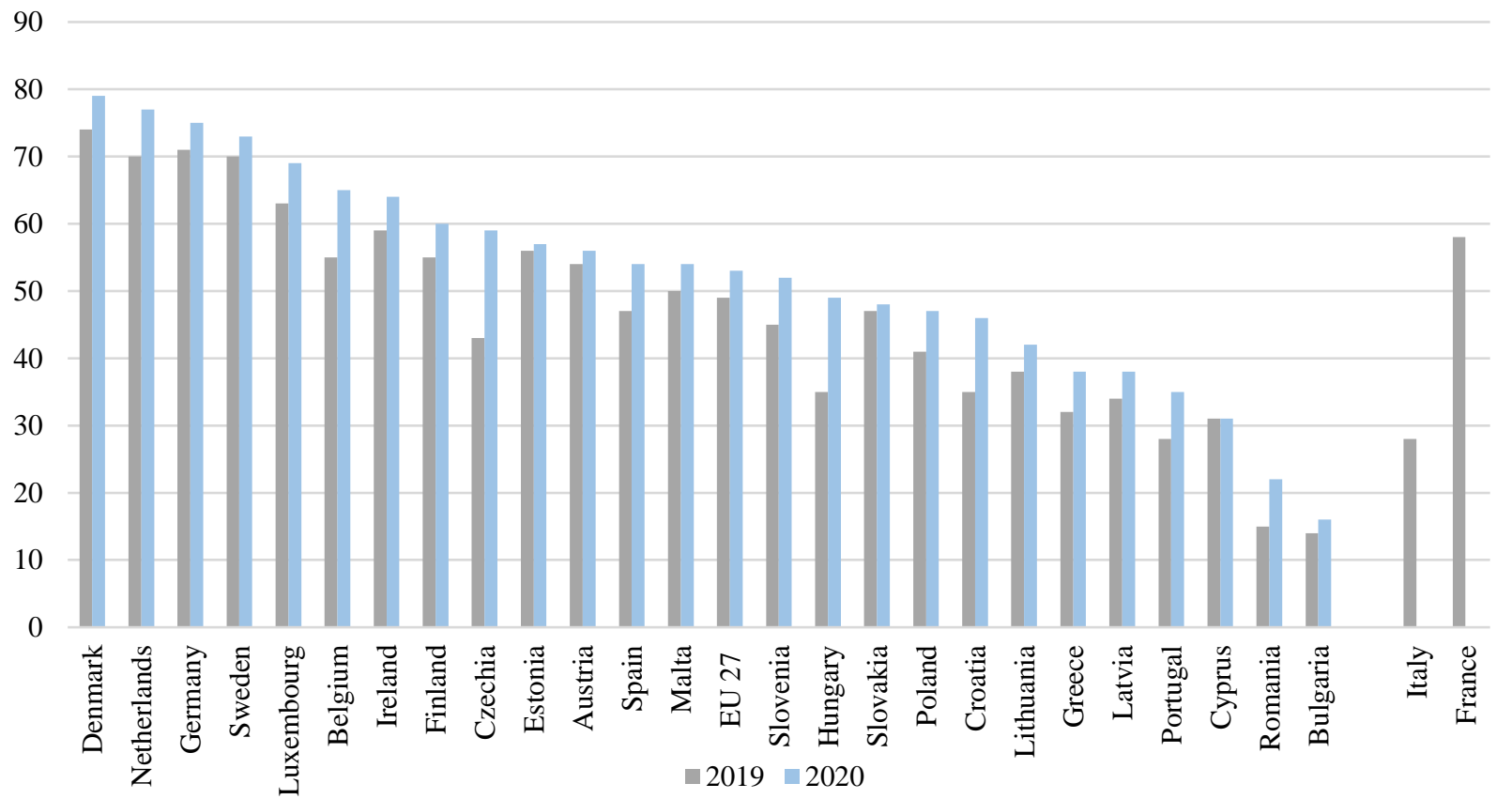

Source: author's creation based on the data from Eurostat, 2021

Fig. 2. Internet purchases by individuals, percentage of individuals, last online purchase in the last 3 months in EU-27 countries, 2019-2020

The analysis about the money spent on internet purchase percentage of individuals who purchased online in the last 3 months in EU-27 countries and in Estonia, Latvia, and Lithuania in 2020 shows (Fig. 3), that on average almost half (46 \%) of Europeans are spending 100-499 euros on their internet purchases in the 3 month period. $12 \%$ are spending less than $50 \%$ and thus are comparably less active online customers, but $11 \%$ are spending between 500 and 999 euros and $7 \%$ are spending more than 1000 euros. If we look at the Baltic States, Estonia equals the EU-27 percentages with the biggest distinction in the percentage of individuals spending more than 1000 euros - which is $12 \%$ and is $5 \%$ higher as the EU average. In Latvia, there are $32 \%$ of individuals in both groups - the ones spending less than 50 euros and the ones spending 100-499 euros. Only $5 \%$ are spending more than 500 euros and only $2 \%$ - more than 1000 euros. Similarly, in Lithuania only $6 \%$ are spending more than 500 euros and $4 \%$ - more than 1000 euros. However, the group of people spending between 100-499 euros are bigger compared to Latvia - $40 \%$, which is closer to the EU-27 average. $21 \%$ of individuals are spending less than 50 euros. These data clearly show the higher activity and larger sums spent by individuals in Estonia and a more conservative attitude towards online shopping by Latvians. 


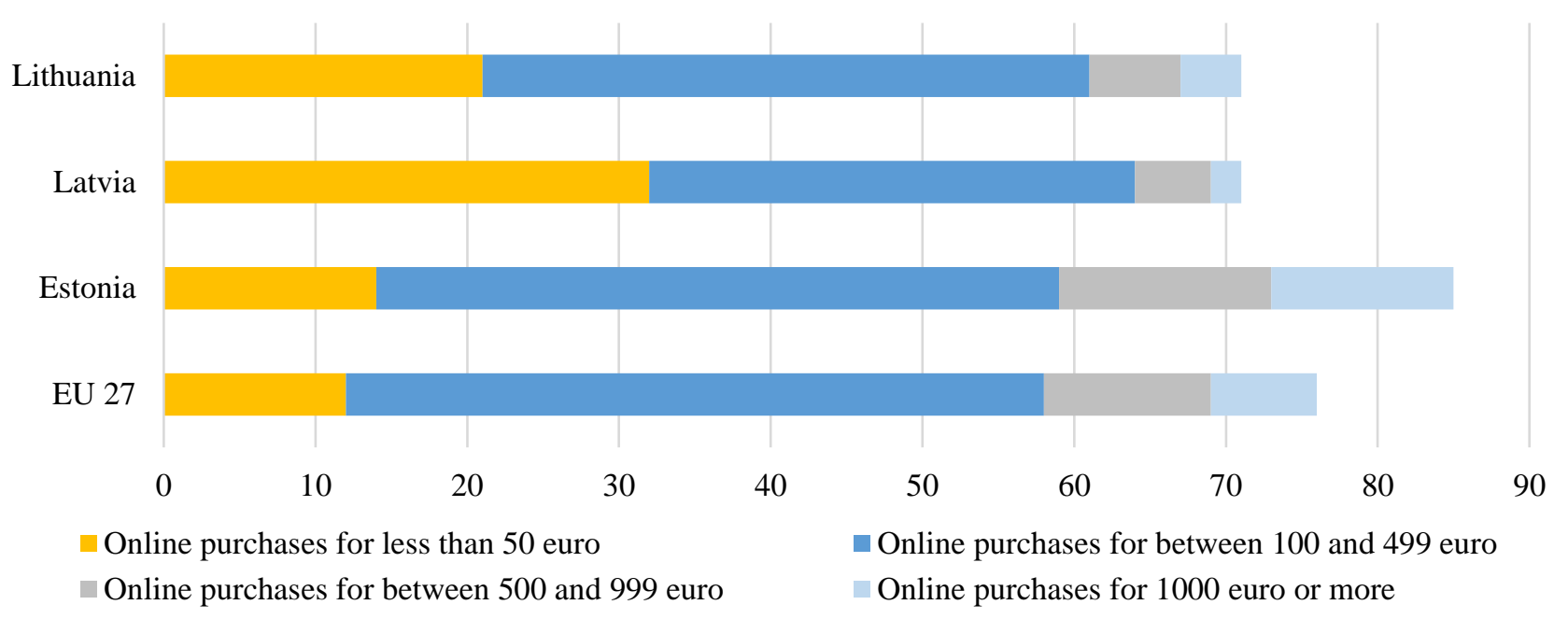

Source: author's creation based on the data from Eurostat, 2021

\section{Fig. 3. Money spent on internet purchase percentage of individuals who purchased online in the last 3 months in EU-27 countries and in Estonia, Latvia, and Lithuania, 2020.}

If we look more specifically on the sector of bioeconomy - the businesses that rely on biological resources - animals, plants, etc and which are also primary production sectors that use and produce biological resources (agriculture, forestry, fisheries, and aquaculture); and all economic and industrial sectors that use biological resources and processes to produce food, feed, bio-based products, energy and services (European Commission, 2018) These sectors have been a focus of the European policy for a decade now with political decision to strengthen the bioeconomy sectors of EU as one of the fundamental resources for a sustainable growth. In the latest action plan for the bioeconomy sector - European Bioeconomy: the European way to use our natural resources (Bioeconomy: the European way.., 2018), which is a follow-up of the European Bioeconomy Strategy in 2012: Sustainable bioeconomy for Europe: strengthening the connection between economy, society, and the environment (updated in 2018) (A sustainable bioeconomy.., 2018), two of the main priorities are linked to the use of bio- resources by accessing new markets - 1.Strenghten and scale-up bio-based sectors, that will be done by unlocking investments and markets and deploying innovative bio-based solutions (..) and 2. Rapidly deploy local bioeconomies across the whole of Europe, for example, via the transition to sustainable food and farming systems (..) and more diversified revenues for farmers, foresters and fishermen (Bioeconomy: the European way.., 2018). These priorities go very well together with the currently trending increase of online sales among which, the sales of bio-based products are also increasing, i.e. the demand for buying local food online provides new market opportunities for farmers, producers and wholesalers, especially in the last year of COVID-19 restrictions. Local food is linked to social embeddedness in the sense of social connections, mutual exchange, and trust that is viewed by some as an important feature of direct agricultural marketing (Hinrichs, 2000; Sage, 2003, Pelse et al, 2015). The concept of local food may also extend to who produced the food: the personality and ethics of the grower; the attractiveness of the farm and surrounding landscape; and other factors that make up the "story behind the food" (Martinez et al. 2010), which holds value in the eyes of customers either buying directly or online.

In 2020, most of the EU countries had some form of restrictions in place regarding the accessibility of nonprimary necessity goods during certain periods of 2020 that fostered the online shopping of such goods as clothing and home goods. The analysis of data of the goods and services that are purchased online related to bioeconomy in EU-27 countries for 2020 indicates that the sector dominating in online sales in 
all EU member states is clothing (including sports clothing), shoes and accessories. In the Netherlands, Germany, and Denmark, more than $50 \%$ of individuals had bought clothing online last year. The percentage of people ordering within the groups of 'Deliveries from restaurants, fast-food chains, catering services"; "Printed books, magazines or newspapers"; "Furniture, home accessories or gardening products" and "Cosmetics, beauty or wellness products" are approximately the same ranging from 17-15 \%. An interesting group of produce is "Food or beverages from stores or from meal kits providers" - on average $11 \%$ of people in EU-27 have ordered food online in 2020, but combined with the group of food deliveries from restaurants, fast-food chains, catering services, which is $17 \%$, it makes one third of Europeans who has ordered food online. In the Netherlands, these two groups combined made $60 \%$ and $57 \%$ in Denmark. Therefore, definitely a remarkable amount of food produce has been ordered online last year that is significant to the bioeconomy sector and indicates the changes in the business module of selling food that might take on more widely in the rest of EU countries.

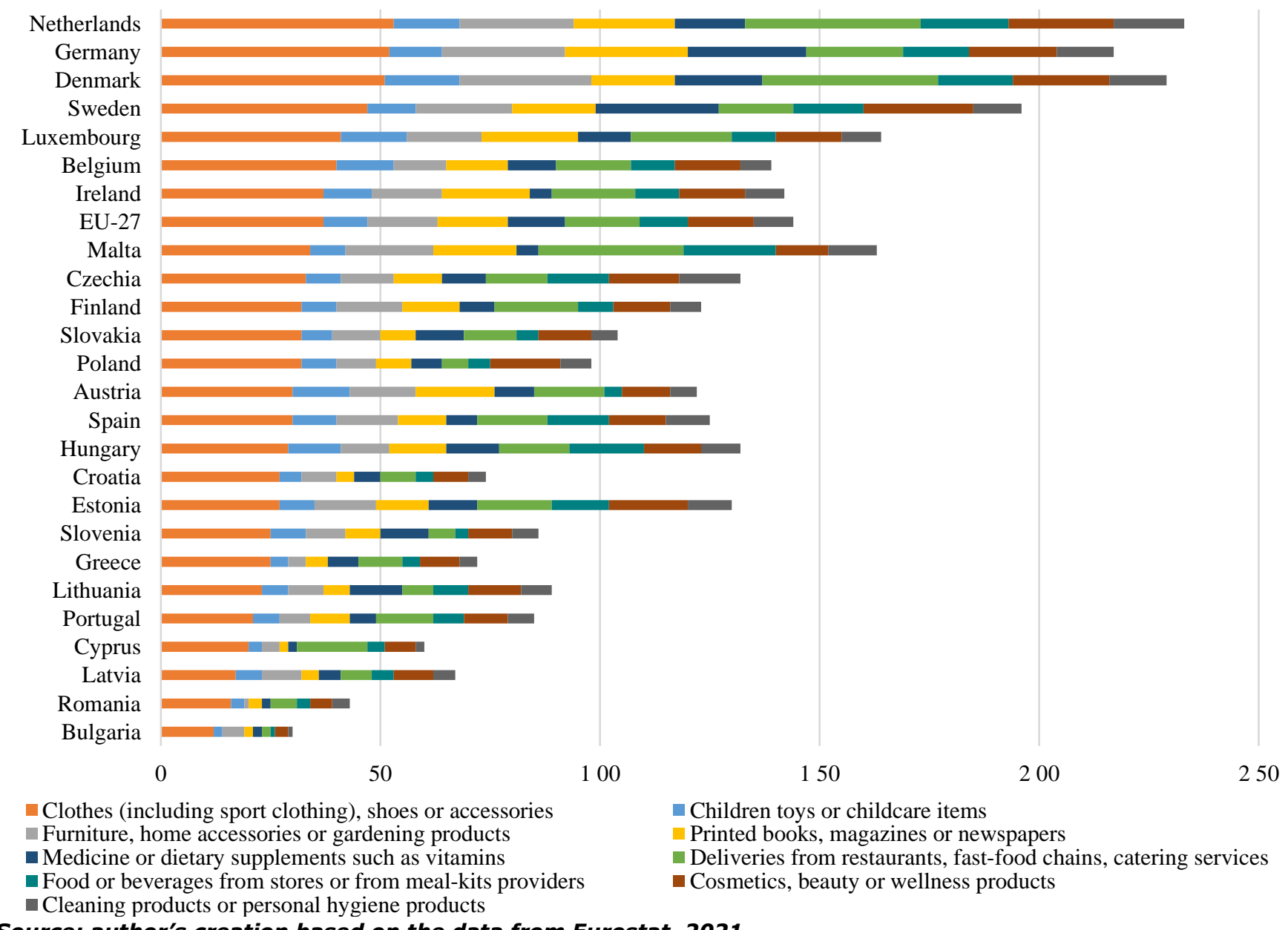

Source: author's creation based on the data from Eurostat, 2021

\section{Fig. 4. Internet purchases - goods or services related to bioeconomy, percentage of individuals who purchased online in the last 3 months in EU-27 countries, 2020}

The data about the country of origin (Fig. 5.) of sellers for internet purchases indicates that half of the sellers for internet purchases in the last 3 months in EU-27 have been national sellers, 17 \% have been from other member states and only $12 \%$ - from the rest of the world. In the Netherlands, Denmark, and Germany, which all have been in the top 3 in internet sales, more than 70 \% of sales are from national sellers. Overall this shows the interest of people buying locally also when using e-commerce and in combination with the analysis of produce bought by the individuals of these countries, it allows to assume 
that online sales are of a growing importance for the bioeconomy sector especially in the groups of food and beverages and food delivery; clothing, furniture, home accessories and gardening products. The same structure of national/international sellers can be observed also in the Baltic States, With Estonia being very close to the EU average of $50 \%$ of goods bought from the national sellers, $18 \%$ from other EU countries and $16 \%$ from the rest of the world. Lithuania is in-between with $37 \%$ bought from national sellers, but only $26 \%$ of online sales in Latvia is from the national sellers. As previously described, Estonia is ahead of other Baltic states in the amount of money spent on online sales and in the analysis of the produce groups bought online and their frequency, it can be concluded that it is similar to the EU countries that are leading the online sales, thus the authors assume that this is the direction also other Baltic States are going in the increase in the groups of food and beverages and food delivery; clothing, furniture, home accessories and gardening products. A wider use of online purchases for the everyday items and buying groceries, buying from local sellers and increasing the frequency and amount spent in online purchases.

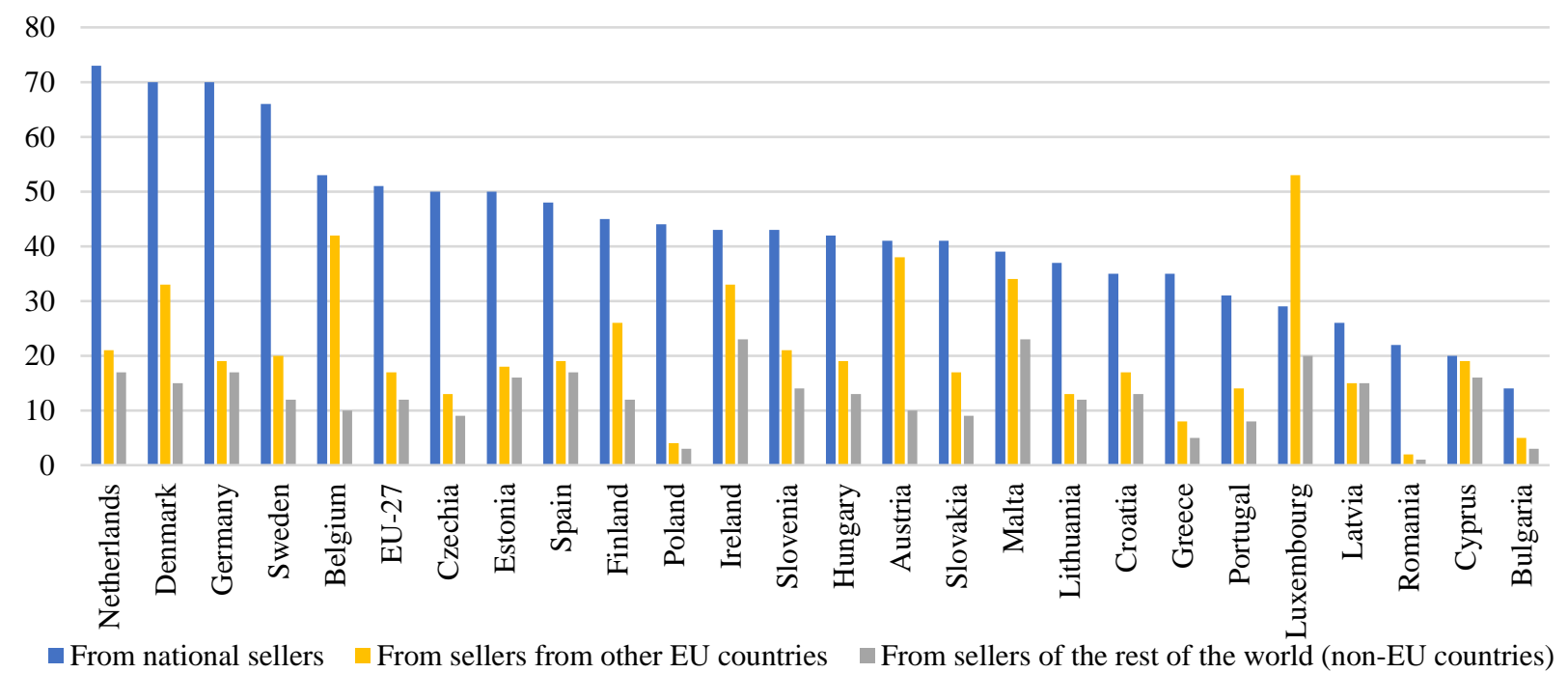

Source: author's creation based on the data from Eurostat, 2021

Fig. 5. Internet purchases - origin of sellers, percentage of individuals that heave done online purchases in the last 3 months in EU-27 countries, 2020

Due to lack of data available for deeper analysis of the digitalisation of bioeconomy sectors in Latvia for the last year, the authors decided to use the data about eSignatures, which is one of the indicators showing the digital transformation in enterprises, state entities and in the life of individuals that has data available already about the COVID-19 period of 2020 in Latvia. The data about the use of eSignatures in Latvia reflect (Fig. 6.) a rapid increase after the COVID restrictions were enforced in March of 2020. To estimate the future trend of the amount of eSignature users Holt's two-parameter model of exponential smoothing, also known as linear exponential smoothing, was used. It is a popular smoothing model for forecasting data on trends. Holt's model has three separate equations that work together to generate a final forecast (Hyndman R. J., Anthanasopoulos G. 2018, Jansons V., Kozlovskis K., 2012).

Forecast equation

$$
\mathrm{y}^{\wedge} \mathrm{t}+\mathrm{h} \mid \mathrm{t}=\ell \mathrm{t}+\mathrm{hbt}
$$

Level equation

$$
\ell t=\alpha y t+(1-\alpha)(\ell t-1+b t-1)
$$

Trend equation 
$\mathrm{bt}=\beta *(\ell \mathrm{t}-\ell \mathrm{t}-1)+(1-\beta *) \mathrm{bt}-1$

Where:

ltt denotes an estimate of the level of the series at time tt,

$b t b t$ denotes an estimate of the trend (slope) of the time series at time tt,

$a a$ is the smoothing parameter for the level $0 \leq a \leq 10 \leq a \leq 1$,

and $\beta * \beta *$ is the smoothing parameter for the trend, $0 \leq \beta \leq 10 \leq \beta \leq 1$.

The first is a basic smoothing equation that directly adjusts the last smoothed value for last period's trend. The trend itself is updated over time through the second equation, where the trend is expressed as the difference between the last two smoothed values. Finally, the third equation is used to generate the final forecast. (Holt's Forecasting.., 2000)

Holt's model uses two parameters, one for the overall smoothing and the other for the trend smoothing equation. The method is also called double exponential smoothing or trend-enhanced exponential smoothing.

R-squared of the applied model is 0.881 , which indicates that the model is sufficiently explaining the data. The values ACF and PACF of residuals are within the confidential intervals, which indicates the statistical insignificance of residuals thus the residuals are stationary.

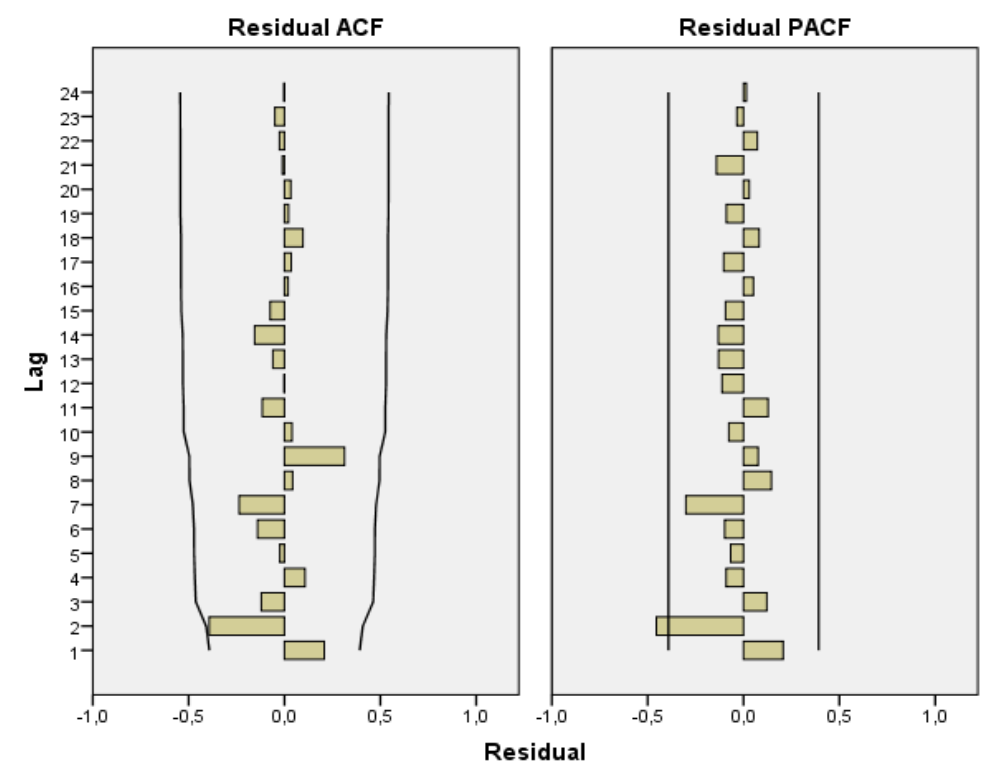

\section{Source: author's creation}

Fig. 6. Values ACF and PACF of residuals after the use of Holt's two-parameter model of exponential smoothing 


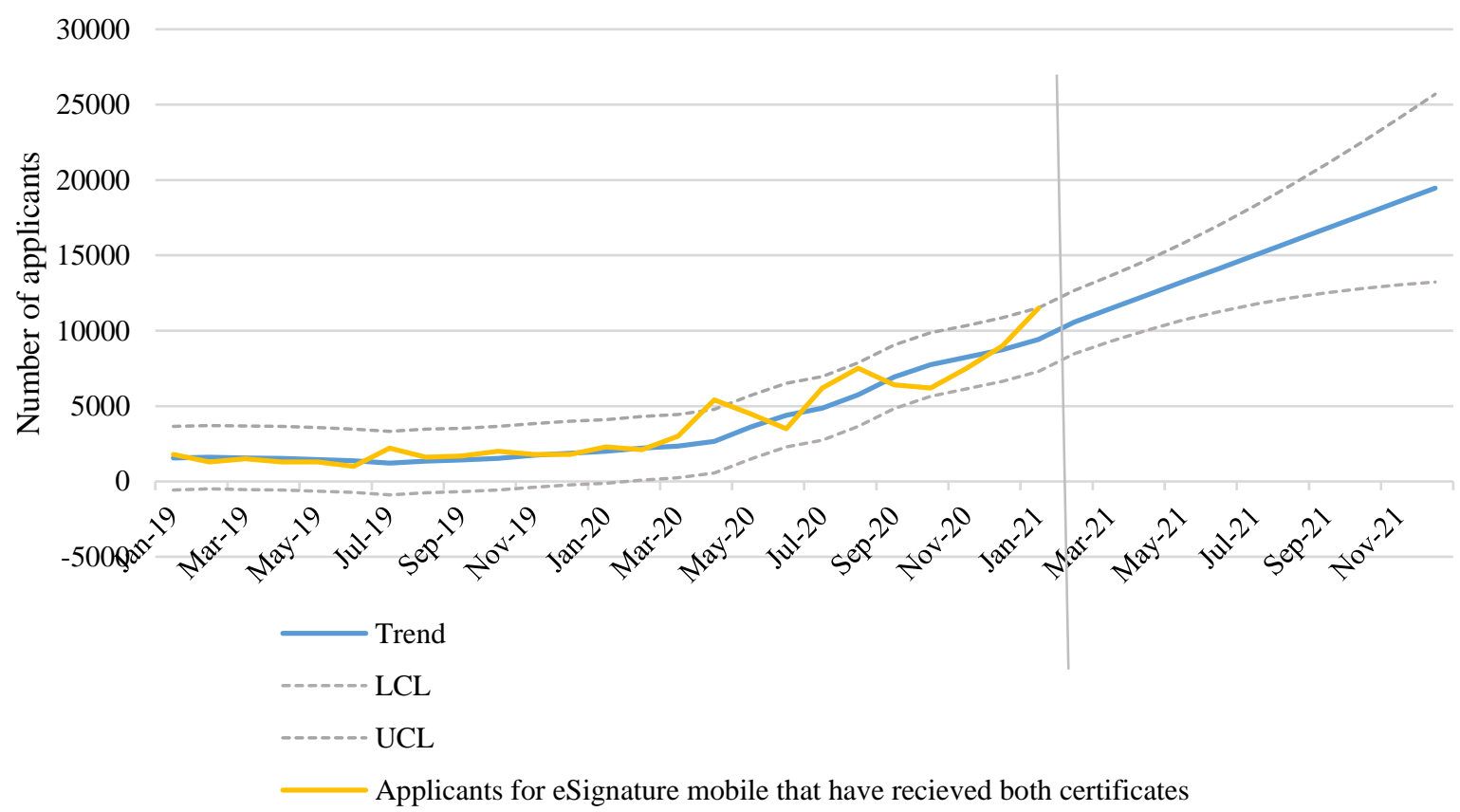

Source: author's creation

Fig. 7. Applicants for eSignature mobile that have received both certificates in Latvia in $\mathbf{2 0 2 0}$ and an estimated trend for $\mathbf{2 0 2 1}$

The data about the applicants for eSignature mobile that have received both certificates (and thus are ready to use the eSignature) in Latvia throughout 2020 and January of 2021 indicates that there is a rather fast growing interest in the application for and use of the eSignature mobile, which is one of the technologies that allows signing documents using the mobile authentication platform and therefore is very user-friendly. The combination of the approachability of this technology and the current necessity to sign e-documents are providing the right circumstances and motivation for the use of this tool. According to the calculated forecast using the Holts model, the applications for the eSignature will continue to increase in 2021 and reach almost 20000 applicants by November of 2021, assuming that the COVID-19 restrictions will still be in place. However, the activity and positive user experience for the use of e-Signatures allows to assume that the use of e-Signatures will not decrease also after the restrictions will be cancelled. The part-distance work module will likely to persist due to the positive effects it brings and thus the need for signing edocuments will remain high. The analysis of these data also indicates a change in the behaviour of state entities, enterprises and individuals towards a more intensive use of the digitalisation tools that will likely transfer to the other digitalisation aspects in the business and household lives.

\section{Conclusions, proposals, recommendations}

1) In 2020, the most active internet customers are from Denmark (79 \%), the Netherlands (77 \%), Germany (75\%), and Sweden (73\%) and the countries comparatively lagging behind are Romania and Bulgaria with $22 \%$ and $16 \%$ respectively. This indicates not only the willingness and readiness of individuals to shop online, but more importantly, the wideness or narrowness of the offered goods online as well as the availability and terms for online orders such as shipping fees. In previous studies, it has been determined that in Latvia the most important factor groups that affect the use of e-commerce are technological development, organisational, legislation, and economic factors. At the same time, language and content barriers as well as the lack of secure payment infrastructure are considered significant barriers avoiding to adapt e-commerce. The authors assume that these barriers might be similar also in other EU member states that are not as active in e-commerce. 
2) We can't be sure how long the COVID-19 will leave an influence on our work and everyday life habits, but we can say with certainty that this time has motivated and pushed people to manage and use the tools of digitalisation that might not be used in such extent in the pre-COVID world. This has opened many opportunities to change the business model and work methods towards more efficient and competitive and these initiatives should be supported as they will be the ones to increase the efficiency and competitiveness in the post-COVID times we are all so eagerly looking forward to.

3) The interest of people buying locally also when using e-commerce and in combination with the analysis of produce bought by the individuals of the most active EU countries in online sales, allows to assume that online sales are of growing importance for the bioeconomy sector especially in the groups of food and beverages and food delivery; clothing, furniture, home accessories and gardening products.

4) Estonia is ahead of other Baltic states in the amount of money spent on online sales and in the analysis of the produce groups bought on lain and their frequency, it can be concluded that it is similar to the EU countries that are leading the online sales, thus the authors assume that this is the direction also other Baltic states are going in - the increase in the groups of food and beverages and food delivery; clothing, furniture, home accessories and gardening products. A wider use of online purchases for everyday items and buying groceries, buying from local sellers, and increasing the frequency and amount spent in online sales.

5) According to the calculated forecast using the Holts model, the applications for the eSignature will continue to increase in 2021 and reach almost 20000 applicants by November of 2021, assuming that the COVID restrictions will still be in place. However, the activity and positive user experience for the use of eSignatures allows to assume that the use of eSignatures will not decrease also after the restrictions will be cancelled. The part-distance work module will likely persist due to the positive effects it brings and thus the need for signing e-documents will remain high. The analysis of these data also indicates a change in the behaviour of state entities, enterprises and individuals towards a more intensive use of the digitalisation tools that will likely transfer to the other digitalisation aspects in the business and household lives.

\section{Acknowledgement}

The paper is supported by the Post-doctoral Research Aid Programme of the State Education Development Agency of the Republic of Latvia, project „'Digitalisation of Enterprises of the Bioeconomy Sector for Increasing their Competitiveness and Exportability" (No. 1.1.1.2/VIAA/3/19/553).

\section{Bibliography}

1. Bioeconomy: the European Way to Use Our Natural Resources. Action plan (2018). Directorate-General for Research and Innovation (European Commission), Retrieved: https://ec.europa.eu/research/bioeconomy/pdf/ec_bioeconomy_booklet_2018.pdf. Access: 03.03.2021.

2. Clauss, T. (2017). Measuring Business Model Innovation: Conceptualization, Scale Development, and Proof of Performance In: R\&D Management, Special Issue: Incubation, Decision Making and Knowledge Interaction in Business Modelling, Volume 47, Issue 3, pp 385-403, DOI: https://doi.org/10.1111/radm.12186

3. Data About the Use of E-Signatures (2021). Press release, Latvia State Radio and Television Centre, Retrieved: https://www.Ivrtc.Iv/jaunumi/eparaksts-tiek-lietots/, Access: 25.01.2021.

4. E-commerce Sales (2021) Eurostat. Retrieved: https://ec.europa.eu/eurostat/databrowser/view/ISOC_EC_ESELN2_custom_654053/default/table?lang=en. Access: 05.03.2021.

5. European Commission (2021). Digital Economy and Society Index (DESI) 2020. Retrieved: https://eufordigital.eu/wp-content/uploads/2020/06/DESI2020Thematicchapters-FullEuropeanAnalysis.pdf, Access: 05.03.2021.

6. Hinrichs, C.C. (2003). The Practice and Politics of Food System Localization, Journal of Rural Studies 19: 33-45.

7. Holt's Forecasting Model (2000) In: Swamidass P.M. (eds) Encyclopedia of Production and Manufacturing Management. Springer, Boston, MA . https://doi.org/10.1007/1-4020-0612-8_409 
8. Hyndman, R.J., Anthanasopoulos, G. (2018). Holt's Trend Methods. Retrieved: http://course1.winona.edu/bdeppa/FIN\%20335/Handouts/Exponential_Smoothing\%20(part\%20.html. Access: 10.02.2021.

9. Internet purchases - Goods or Services (2020 onwards) (2021) Eurostat. Retrieved: https://ec.europa.eu/eurostat/databrowser/view/ISOC_EC_IBGS_custom_745233/default/table. Access: 15.03.2021.

10. Internet purchases - Money Spent (2020 onwards) (2021) Eurostat. Retrieved: https://ec.europa.eu/eurostat/databrowser/view/ISOC_EC_IBM_custom_663438/default/table?lang=en . Access: 10.03.2021.

11. Internet purchases - Origin of Sellers (2020 onwards) (2021) Eurostat. Retrieved: https://ec.europa.eu/eurostat/databrowser/view/isoc_ec_ibos/default/table?lang=en lang=en. Access: 15.03.2021.

12. Internet Purchases by Individuals (2020 onwards) (2021) Eurostat. Retrieved: https://ec.europa.eu/eurostat/databrowser/view/isoc_ec_ib20/default/table?lang=en. Access: 05.03.2021.

13. Internet Purchases By Individuals (until 2019) (2020) Eurostat. Retrieved: https://ec.europa.eu/eurostat/databrowser/view/isoc_ec_ibuy/default/table?lang=en. Access: 10.03.2021.

14. Jansons, V., Kozlovskis, K. (2012). Ekonomiska Prognozesana SPSS 20 Vide. Rigas Tehniska universitate, pp 547

15. Jekabsone, I., Gudele, I. (2020). Factors Contributing to the Regional Development of E-Commerce in Latvia. In: Proceedings of the 2020 International Conference "Economic Science for Rural Development" No 53, pp. 177-185.

16. Martinez, S.; Hand, M.; Da Pra, M.; Pollack, S.; Ralston, K.; Smith, T.; Vogel, S.; Clark, S.; Lohr, L.; Low, S.; Newman, C. (2010). Local Food Systems: Concepts, Impacts and Issues. Retrieved from: http://www.ers.usda.gov/media/122868/err97_1_.pdf

17. Pelse, M., Lescevica M. (2020). Analysis of Digitalization Referred to in Strategic Policy Documents in the Lifelong Education Context. In: Proceedings of the 2020 International Conference "Economic Science for Rural Development" No 54, pp. 249-257.

18. Pelse M., Zeverte-Rivza S. (2015) Innovations and the Use of Information and Communication Technologies in Entrepreneurship in Latvia. In: Proceedings of the International Scientific Conference Engineering for Rural Development, pp 681 - 687, ISSN 1691-5976

19. Pelse M., Zeverte-Rivza S., Rone Z. (2015). Sustainable Innovations in the Promotion of Home Produced Products in the Market. In: Journal of Security and Sustainability Issues, vol 5, no 2, pp. 259-267

20. Sage, C. (2003). Social Embeddedness and Relations of Regard: Alternative 'Good Food' Networks in SouthWest Ireland, Journal of Rural Studies 19: 47-60

21. Schallmo, D, Christopher, A., Boardman, W., Boardman, L. (2017). Digital Transformation of Business Models - Best Practice, Enablers, and Roadmap. In: International Journal of Innovation Management 21(1):1740014, DOI: $10.1142 / \mathrm{S} 136391961740014 \mathrm{X}$

22. Sustainable Bioeconomy for Europe: Strengthening the Connection Between Economy, Society, and the Environment, Updated Bioeconomy Strategy (2018) Directorate-General for Research and Innovation (European Commission). Retrieved: https://op.europa.eu/en/publication-detail//publication/edace3e3-e189-11e8-b690-01aa75ed71a1. Access: 03.03.2021. 